\section{Compassionate Use of a Single Dose of Benralizumab in a Near-Fatal Asthma Exacerbation}

Pérez de Llano L ${ }^{1}$, Blanco Cid N ${ }^{1}$, Ortiz Piquer $\mathrm{M}^{2}$, Dacal Rivas $\mathrm{D}^{1}$ ${ }^{\prime}$ Pneumology Service, Hospital Lucus Augusti, Lugo; EOXI Lugo, Cervo e Monforte, Lugo, Spain

${ }^{2}$ Intensive Care Unit, Hospital Lucus Augusti, Lugo; EOXI Lugo, Cervo e Monforte, Lugo, Spain

J Investig Allergol Clin Immunol 2021; Vol. 31(3): 268-270 doi: 10.18176/jiaci.0609

Key words: Asthma. Benralizumab. Asthma attack. Asthma exacerbation.

Palabras clave: Asma. Benralizumab. Ataque de asma. Exacerbación del asma.

A 23-year-old male active smoker who occasionally used illicit drugs (cocaine and marijuana) and had been diagnosed with early-onset allergic asthma was admitted to the respiratory care unit for a severe asthma exacerbation. His medical history included several hospital admissions during childhood (the last of them at the age of 8 years), positive skin prick test results for house dust mites, and an average of 2 severe exacerbations per year. The patient acknowledged that he had stopped maintenance beclomethasone dipropionate and formoterol fumarate during the preceding 6-8 weeks and had only taken albuterol several times a day. On admission, the patient's vital signs were as follows: temperature, $37.3^{\circ} \mathrm{C}$; blood pressure, 130/65; pulse, $98 \mathrm{bpm}$; respiratory rate, 40 breaths/min. Blood cultures and antigen tests for detection of Streptococcus pneumoniae and Legionella pneumophila in urine were negative. Polymerase chain reaction (buccal swab) for influenza A, influenza B, and respiratory syncytial virus was negative. Blood arterial gas analysis revealed hypercapnia $\left(\mathrm{PaCO}_{2}, 6.9 \mathrm{mmHg}\right.$; blood pressure, $\left.52 \mathrm{mmHg}\right)$, and the blood eosinophil count was $600 / \mu \mathrm{L}$. Values for $\mathrm{C}$-reactive protein and procalcitonin were normal. Toxicology testing for illicit drugs was negative. Initial treatment included supplemental oxygen, short-acting $\beta_{2}$ agonists, and intravenous methylprednisolone $(40 \mathrm{mg} / 6 \mathrm{~h})$. Despite these treatments, the patient's clinical condition deteriorated, and intravenous magnesium and intravenous aminophylline were added to this regimen. However, the patient developed respiratory acidosis $\left(\mathrm{PaCO}_{2}, 52 \mathrm{mmHg} ; \mathrm{pH}, 7.27\right)$ and was transferred to the intensive care unit (ICU), where he underwent orotracheal intubation and mechanical ventilation the day after admission.

Mechanical ventilation and intensive therapy with the aforementioned medications did not improve his respiratory status (Table). Because of the persistent critical clinical status and the eosinophilia at admission, we decided to administer subcutaneous benralizumab $30 \mathrm{mg}$ on the fourth day of ICU admission. Because the patient was unconscious, informed consent was obtained from his mother. His respiratory condition improved considerably 4 days after administration of benralizumab, with normalization of $\mathrm{pH}$ and decreased peak inspiratory pressure and airway resistance (Table). The patient was extubated on ICU day 13, that is, 9 days after his benralizumab injection, and recovered completely. The methylprednisolone dose was tapered from day 4 after the injection until day 16, and the patient was discharged 25 days after admission.

As far as we know, this is the first published case of compassionate use of the anti-IL-5R $\alpha$ humanized IgG1 $\kappa$ monoclonal antibody benralizumab [1] in a patient who needed mechanical ventilation because of a near-fatal asthma attack,

Table. Blood Gas Values and Respiratory Mechanics Before and After Administration of Benralizumaba

\begin{tabular}{|c|c|c|c|c|c|c|c|c|c|c|c|c|}
\hline \multirow[t]{2}{*}{ Variables } & \multicolumn{12}{|c|}{ Days Before and After Administration } \\
\hline & -4 & -3 & -2 & -1 & 0 & +1 & +2 & +3 & +4 & +5 & +6 & +7 \\
\hline $\mathrm{pH}$ & 7.29 & 7.31 & 7.32 & 7.37 & 7.37 & 7.31 & 7.35 & 7.32 & 7.34 & 7.34 & 7.41 & 7.45 \\
\hline $\mathrm{PaCO}_{2}$ & 52 & 61 & 70.3 & 61.5 & 72.5 & 82.1 & 78.8 & 83.6 & 75.8 & 63.7 & 53.6 & 42.6 \\
\hline $\mathrm{PaO}_{2}$ & 46.5 & 99.5 & 103 & 69.2 & 61.4 & 59 & 52.8 & 98.8 & 93.6 & 158 & 76.2 & 93 \\
\hline $\mathrm{FiO}_{2}(\%)$ & 50 & 39 & 34 & 34 & 39 & 43 & 42 & 46 & 44 & 39 & 39 & 43 \\
\hline $\mathrm{TV}(\mathrm{mL})$ & 536 & 442 & 484 & 512 & 466 & 507 & 500 & 531 & 615 & 722 & 816 & 585 \\
\hline MV (L/min) & 12.3 & 10.5 & 11.4 & 12.2 & 10.5 & 9.6 & 7.3 & 9.2 & 9.9 & 10.4 & 9.7 & 11.7 \\
\hline $\mathrm{PIP}\left(\mathrm{cm} \mathrm{H}_{2} \mathrm{O}\right)$ & 41 & 35 & 36 & 35 & 30 & 29 & 41 & 36 & 24 & 22 & 25 & 23 \\
\hline $\mathrm{mAWP}\left(\mathrm{cm} \mathrm{H}_{2} \mathrm{O}\right)$ & 15 & 15 & 18 & 17 & 11 & 13 & 18 & 18 & 12 & 13 & 17 & 14 \\
\hline $\operatorname{PEEP}\left(\mathrm{cm} \mathrm{H}_{2} \mathrm{O}\right)$ & 6 & 6 & 10 & 9 & 1 & 6 & 12 & 10 & 5 & 10 & 10 & 8 \\
\hline $\operatorname{Raw}\left(\mathrm{cm} \mathrm{H}_{2} \mathrm{O} / \mathrm{L} / \mathrm{sg}\right)$ & 126.83 & 114.28 & 94.73 & 88.52 & 108.57 & 100 & 189.04 & 117.39 & 72.72 & 51.92 & 49.48 & 46.15 \\
\hline
\end{tabular}

Abbreviations: FiO2, fraction of inspired oxygen; mAWP, mean airway pressure; MV, minute ventilation; PCO2, indicates partial pressure of carbon dioxide; PEEP, positive end-expiratory pressure; PIP, peak inspiratory pressure; p02, partial pressure of oxygen; Raw, airway resistance; TV, tidal volume. aGreen rows: relevant mechanical ventilation parameters, lung mechanical characteristics, and arterial blood gas values. Yellow column: day zero, administration of dose of benralizumab. Amber column: day 4 after benralizumab injection when we observed improvement in mechanical ventilation measurements. 
maybe due to nonadherence to regular medication and overuse of albuterol [2]. We cannot assert that the benralizumab administered was responsible for the favorable clinical outcome and that the patient would have made a full recovery with only short-acting $\beta_{2}$ agonists and systemic corticosteroids. Indeed, the duration of mechanical ventilation (13 days) did not differ from values reported elsewhere [3]. Nevertheless, it should be taken into account that the patient had not responded to a previous aggressive therapeutic approach.

The biology of life-threatening asthma attacks remains unclear, although eosinophils present a widespread distribution within the respiratory tract in fatal cases whereas neutrophils can participate in specific situations, such as sudden-onset fatal asthma, mainly affecting the small airways [4]. In the present case, the patient had a T2-high asthma phenotype (allergic, early-onset, eosinophilic asthma), but he did not respond to high doses of corticosteroids. This might be explained by a shift in the underlying inflammatory process, which seemed to be neutrophil-dominant, and/or by the presence of eosinophilic inflammation with relative insensitivity to corticosteroids, a condition that has been found in about $25 \%$ of poorly controlled asthmatics after 7-12 days taking oral prednisolone $30 \mathrm{mg} / \mathrm{d}$ [5].

We chose benralizumab because it has enabled the prednisolone dose to be reduced in chronic uncontrolled asthma [6] and because we hypothesized that an ongoing eosinophilic inflammation could have been present in the airways despite complete suppression of blood eosinophils after systemic corticosteroid therapy. On the other hand, Laviolette et al [7] observed that peripheral blood eosinophil counts were undetectable at 1 day after administration of subcutaneous benralizumab and remained depleted throughout the 84 days of the study. While these authors administered doses (100 and $200 \mathrm{mg}$ ) above those that are used in clinical practice $(30 \mathrm{mg}$ ) and the significant decrease in the percentage of sputum eosinophils (from $4.6 \%$ to $0.6 \%$ ) was reported at day 28 , the biological effects seem to occur early on with this drug. In fact, a patient with a severe asthma attack in whom systemic corticosteroids were contraindicated achieved significant clinical and functional improvement within 19 hours after subcutaneous injection of benralizumab $30 \mathrm{mg}$ [8]. Besides, Tello et al [9] reported the case of a patient who experienced a life-threatening exacerbation and improved considerably 2 days after a single dose of subcutaneous mepolizumab. Monoclonal antibodies (mAbs) are high-molecular-weight compounds, and for those administered subcutaneously, absorption into the systemic circulation first requires transport of the drug through the interstitial space into the lymphatic system. Thus, absorption of mAbs after subcutaneous administration is a slow process, with an average time to peak concentration (Tmax) of 6-8 days [10], which fits nicely with the time period the patient in the present case started to show an improvement in his medical condition (4 days) and makes it difficult to understand the rapid response to benralizumab described by Ramakrishnan et al [9].

Taken together, both our case and the others discussed here underline the need for a more comprehensive knowledge of the pharmacokinetics of mAbs in the setting of severe asthma. However, they do open a window of opportunity for the treatment of life-threatening eosinophilic asthma attacks.

\section{Funding}

The authors declare that no funding was received for the present study.

\section{Conflicts of Interest}

Dr Pérez de Llano reports grants, personal fees and nonfinancial support from AstraZeneca, personal fees and nonfinancial support from GSK, grants and personal fees from TEVA, personal fees and nonfinancial support from Novartis, personal fees and nonfinancial support from Chiesi, personal fees and nonfinancial support from Boehringer, personal fees from Sanofi, personal fees from Menarini, personal fees and nonfinancial support from Mundipharma, grants and personal fees from Esteve, personal fees from ROVI, personal fees from BIAL, personal fees from MSD, personal fees from TECHDOW PHARMA, and nonfinancial support from FAES outside the submitted work.

Dr Dacal Rivas reports personal fees and nonfinancial support from Esteve, personal fees and nonfinancial support from Boehringer-Ingelheim, nonfinancial support from GSK, nonfinancial support from Novartis, nonfinancial support from TEVA, nonfinancial support from Chiesi, and nonfinancial support from Ferrer outside the submitted work.

The remaining authors declare that they have no conflict of interests.

\section{References}

1. Dávila González I, Moreno Benítez F, Quirce S. Benralizumab: A New Approach for the Treatment of Severe Eosinophilic Asthma. J Investig Allergol Clin Immunol. 2019;29(2):84-93.

2. Nwaru BI, Ekström M, Hasvold P, Wiklund F, Telg G, Janson C. Overuse of short-acting $\beta 2$-agonists in asthma is associated with increased risk of exacerbation and mortality: $A$ nationwide cohort study of the global SABINA programme. Eur Respir J. 2020;5(4):1901872.

3. Al-Dorzi HM, Al-Shammary HA, Al-Shareef SY, Tamim HM, Shammout K, Dawood AA, et al. Risk Factors, management and outcomes of patients admitted with near fatal asthma to a tertiary care hospital in Riyadh. Ann Thorac Med. 2014;9(1):33-8.

4. Nowak RM, Parker JM, Silverman RA, Rowe B, Smithline $H$, Khan $F$, et al. A randomized trial of benralizumab, an antiinterleukin 5 receptor $\alpha$ monoclonal antibody, after acute asthma. Am J Emerg Med. 2015;33(1):14-20.

5. Colice GL, Stampone P, Leung DY, Szefler SJ. Oral corticosteroids in poorly controlled asthma. J Allergy Clin Immunol. 2005;115(1):200-1.

6. Nair P, Wenzel S, Rabe KF, Bourdin A, Lugogo NL, Kuna P, et al. Oral Glucocorticoid-Sparing Effect of Benralizumab in Severe Asthma. N Engl J Med. 2017;376(25):2448-58.

7. Laviolette M, Gossage DL, Gauvreau G, Leigh R, Olivenstein R, Katial $R$, et al. Effects of benralizumab on airway eosinophils 
in asthmatic patients with sputum eosinophilia. J Allergy Clin Immunol. 2013;132(5):1086-96.

8. Ramakrishnan S, Camp JR, Vijayakumar B, Harding FM, Downs ML, Russell REK, et al. The Use of Benralizumab in the Treatment of Near Fatal Asthma: A New Approach [published online ahead of print, 2020 Feb 5]. Am J Respir Crit Care Med. 2020;10.1164/rccm.202001-0093LE.

9. Tello K, Hoffmann A, Beutel B, Greulich T, Vogelmeier CF, Richter MJ, et al. Anti-interleukin-5 therapy (mepolizumab) in life-threatening asthma attack: A case-based discussion. Respir Med Case Rep. 2019;28:100927.

10. Ryman JT, Meibohm B. Pharmacokinetics of monoclonal antibodies. CPT Pharmacometrics Syst Pharmacol. 2017;6(9):576-88.

Manuscript received May 21, 2020; accepted for publication August 31, 2020.

Nagore Blanco Cid

Pneumology Service

Hospital Universitario Lucus Augusti

Lugo, Spain

E-mail: naggoreich_soleil@hotmail.com 